\title{
LETTER
}

\section{Should persons with autosomal dominant AD be included in clinical trials? Authors' response}

\author{
Kinga Szigeti and Rachelle S Doody* \\ See related review by Szigeti and Doody, http://alzres.com/content/3/1/4, and related letter by Grill and Ringman, \\ http://alzres.com/content/3/3/18
}

We would like to thank Grill and Ringman [1] for their thoughtful response to our article [2] in which we made the case that both early-onset sporadic Alzheimer's disease (AD) cases and known or suspected mutation carriers should generally be enrolled in clinical trials. There is consensus between our groups that excluding patients on the basis of age criteria alone is not valid. In regard to enrollment of patients with known or suspected autosomal dominant $\mathrm{AD}$, the authors caution that these subjects may have a different response or different sideeffect profile to a given intervention. We considered this possibility in our review; however, there are no human data and only scant preclinical data to support this hypothesis. Available preclinical studies so far are insufficient to support excluding all mutation carriers from all trials. Furthermore, it is likely that sporadic AD populations also contain between-subject differences that could produce differences in the magnitude or likelihood of response to a treatment as well as differences in side effects. Random assignment of subjects in clinical trials is designed to counter such unknown differences. Although it is possible that preclinical development programs may uncover a rationale for excluding a particular mutation from a particular trial, our conclusion was that, until there are sufficient clinical trials that include mutation carriers alone or as a separate arm, these individuals should have the right to participate and should not be excluded categorically.

\section{Abbreviations \\ AD, Alzheimer's disease.}

\section{Competing interests}

The authors declare that they have no competing interests.

Published: 23 May 2011

\section{References}

1. Grill JD, Ringman JM: Should persons with autosomal dominant AD be included in clinical trials? Alzheimers Res Ther 2011, 3:18.

2. Szigeti K, Doody RS: Should EOAD patients be included in clinical trials? Alzheimers Res Ther 2011, 3:4.

doi:10.1186/alzrt81

Cite this article as: Szigeti K, Doody RS: Should persons with autosomal dominant AD be included in clinical trials? Authors' response. Alzheimer's Research \& Therapy 2011, 3:19.

*Correspondence: rdoody@bcm.tmc.edu

Department of Neurology, Baylor College of Medicine, One Butler Boulevard, Suite E5.101, Houston, TX 77030, USA 